\title{
THE
}

1993

\section{A Simple Method for Measuring Deep Convection}

\author{
Edward J. Kearns \\ Hans Thomas Rossby \\ University of Rhode Island, trossby@uri.edu
}

Follow this and additional works at: https://digitalcommons.uri.edu/gsofacpubs

Terms of Use

All rights reserved under copyright.

\section{Citation/Publisher Attribution}

Kearns, E.J. \& H.T. Rossby (1993). A Simple Method for Measuring Deep Convection. J. Atmos. Oceanic Technol., 10, 609-617,. doi: 10.1175/1520-0426(1993)0102.0.C0;2

Available at: https://doi.org/10.1175/1520-0426(1993)010\%3C0609:ASMFMD\%3E2.0.C0;2

This Article is brought to you for free and open access by the Graduate School of Oceanography at DigitalCommons@URI. It has been accepted for inclusion in Graduate School of Oceanography Faculty Publications by an authorized administrator of DigitalCommons@URI. For more information, please contact digitalcommons-group@uri.edu. 


\title{
A Simple Method for Measuring Deep Convection
}

\author{
EDWARD J. KEARNS AND H. THOMAS ROSSBY \\ Graduate School of Oceanography, University of Rhode Island, Narragansett, Rhode Island
}

(Manuscript received 21 July 1992, in final form 4 January 1993)

\begin{abstract}
The glass-pipe technology used for RAFOS floats is applied to the monitoring of convection in deep mixed layers. The velocity of a vertical current is estimated from the relationship between the drag force exerted on a float by the vertical current and the buoyancy force induced by the float's resultant displacement from hydrostatic equilibrium. Tests conducted in the winters of 1990 and 1991 in the $18^{\circ} \mathrm{C}$ waters of the northwestern Sargasso Sea reveal definite convective events. Vertical velocities of both upwelling and downwelling plumes are estimated to approach maxima nearing $0.05 \mathrm{~m} \mathrm{~s}^{-1}$, with durations of up to $2 \mathrm{~h}$. One float that crossed the Gulf Stream and entered the Newfoundland Basin showed evidence of very active vertical currents in the near-surface waters with maximum velocities greater than $0.09 \mathrm{~m} \mathrm{~s}^{-1}$.
\end{abstract}

\section{Introduction}

When a warm water mass loses heat to an overlying cool air mass, deep convective mixing may be induced. Surface waters become cold and dense enough to sink, in turn displacing waters from depth to the surface to be subjected to the same cooling conditions. A wellmixed, nearly homogeneous layer of water is the result.

Areas in the oceans where deep convection processes have been observed are the subpolar North Atlantic (McCartney and Talley 1982; Gascard and Clarke 1983 ) and the northwestern Mediterranean (Voorhis and Webb 1970; Schott and Leaman 1991). Various methods have been used to determine the vertical velocities characteristic of upwelling and downwelling convective plumes of seawater in regions of intense cooling. Voorhis and Webb (1970) as well as Gascard and Clarke (1983) deployed free-drifting isobaric floats with vanes to induce a rotational motion in the presence of vertical currents; Schott and Leaman (1991) used moored upward-looking acoustic Doppler current profilers (ADCP) to observe convective events. In this study, RAFOS glass-pipe technology (Rossby et al. 1986 ) is applied to measure the vertical velocities of seawater undergoing buoyancy-driven convection.

A RAFOS float is a cylindrical glass pipe of approximately $2 \mathrm{~m}$ in length and $0.1 \mathrm{~m}$ in diameter. The glass housing contains electronics and instrumentation that listen for sound (for use in tracking the float), measure ambient pressure and temperature, store data, and transmit the data to a satellite. A float's mass may be adjusted by adding or removing ballast so that the float

Corresponding author address: Dr. Edward J. Kearns, Graduate School of Oceanography, University of Rhode Island, South Ferry Road, Narragansett, RI 02882. will remain isobaric in water of a particular density. When an isobaric float is in hydrostatic equilibrium, it will remain on a constant pressure surface; since local horizontal pressure gradients are very small, an isobaric float will remain very nearly at a constant depth. If the float is subjected to a vertical current, the drag force induced on it by that current will displace the float from its hydrostatic equilibrium depth. Knowing the magnitude of the displacement (from pressure measurements made by the float) and, hence, the buoyancy restoring force, the vertical velocity of the current may be estimated from a quadratic relationship between the vertical velocity and the resulting drag force. While this nonlinear relationship will cause a nonrotating float's measurements of small vertical velocities to be less accurate than those measurements made with a rotating float (Voorhis and Webb 1970; Gascard and Clarke 1983), intense vertical currents may still be accurately measured. Nonrotating floats that are released in the mixed layer of a water mass that is undergoing intense cooling can be used in a simple way to obtain accurate measurements of the resulting convective motions.

The water mass used to evaluate the technique established in this study is the so-called $18^{\circ} \mathrm{C}$ water (Worthington 1959). The physical properties of this body of water have been remarkably stable and well defined for decades (Jenkins 1982). This well-known water mass of the western North Atlantic is formed in winter by deep convection due to intense cooling by cold, dry continental air masses. The thermocline developed during the previous summer is eroded, exposing the deep $(200-400 \mathrm{~m}) 18^{\circ} \mathrm{C}$ waters to the cooling process; the result is a well-mixed and nearly homogeneous water mass (Talley and Raymer 1982).

Vertical velocities associated with convective mo- 
tions have been observed to attain magnitudes on the order of centimeters per second. Voorhis and Webb (1970) and Schott and Leaman (1991) reported Mistral-driven convective vertical velocity maxima of 0.025 and $0.10 \mathrm{~m} \mathrm{~s}^{-1}$, respectively. Gascard and Clarke (1983) observed peak vertical velocities of $0.09 \mathrm{~m} \mathrm{~s}^{-1}$ in the Labrador Sea.

\section{Method}

Free-drifting isobaric floats are used to measure convective activity by their response to vertical currents. This concept is based on the probability that the float will encounter upwelling and downwelling plumes of seawater during times of intense cooling. From sequential pressure and temperature measurements made by the float, the vertical velocity of the plume as well as the amount of time the float spends within it can be determined. When combined, these measurements give a good estimate of the event's intensity and a minimum estimate of its duration. The height and width of these plumes cannot be determined.

An isobaric RAFOS float responds to vertical currents by being displaced from its hydrostatic equilibrium depth by a vertical drag force on the float (Fig. 1 ). From this response it is possible to estimate the velocity of the vertical current to which the float is subjected. It should be noted that no extra appendages, such as vanes or drogues, were needed to convert a standard RAFOS float to perform this new mission. Only a minor software change was needed to adapt a generic RAFOS float from its original role as a longrange acoustic Lagrangian tracking device. To enable greater storage of pressure and temperature data in the limited memory of the float, the acoustic tracking of these floats was not utilized in this study.

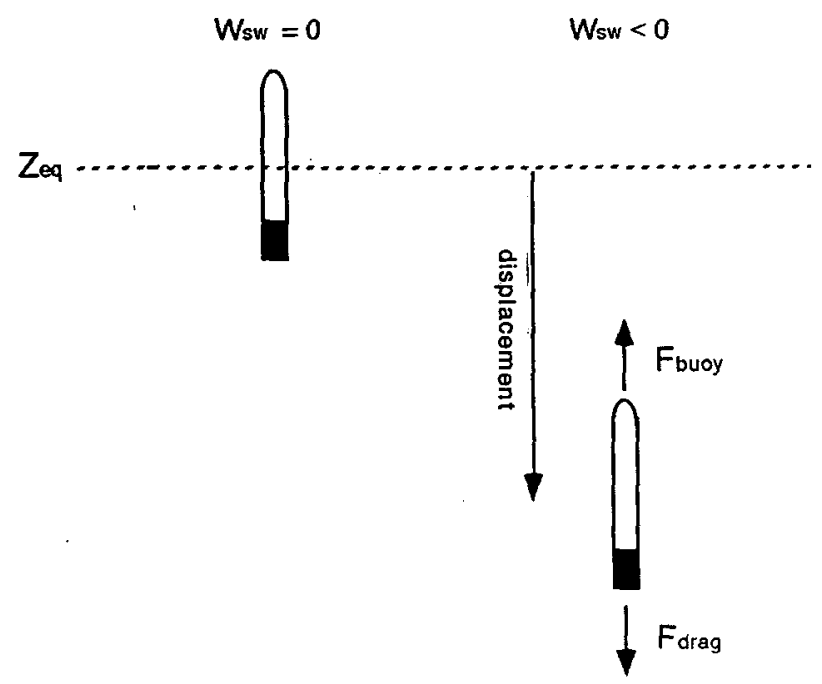

FIG. 1. The forces acting on a RAFOS float. Vertical currents ( $w_{\text {sw }}$ $\neq 0$ ) will induce a drag force that accelerates the float away from its level of hydrostatic equilibrium $Z_{\mathrm{eq}}$, resulting in an increase in the buoyancy restoring force.

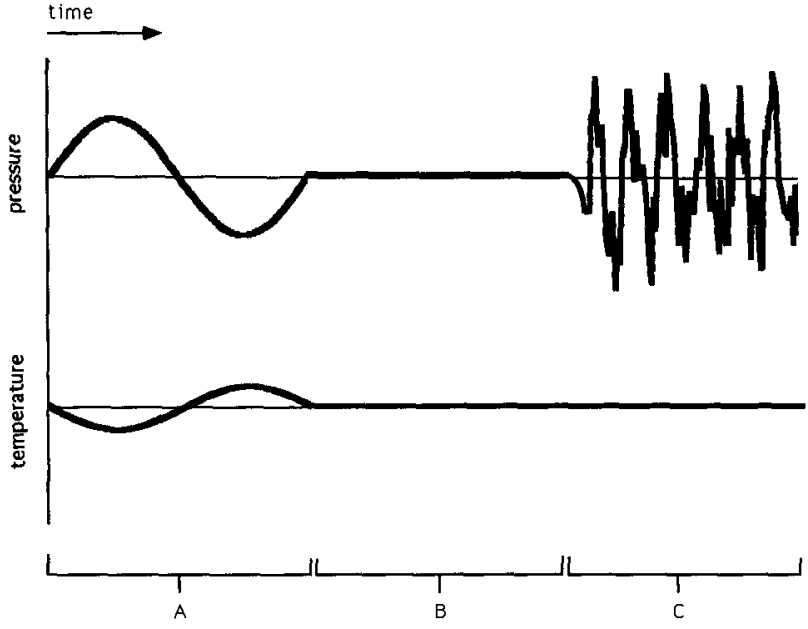

FIG. 2. Schematic float pressure and temperature records. During period $\mathrm{A}$, the float's pressure and temperature records are active and tend to be out of phase, indicating the presence of internal wave activity. In period B, both the pressure and temperature records are constant, indicating that there are no vertical motions active and the float is at its hydrostatic equilibrium pressure. During $C$, the temperature is constant but the pressure record exhibits short time-scale fluctuations; this indicates that the float is in a well-mixed layer and subject to convective motions.

A schematic representation of the pressure and temperature measurements of an isobaric float responding to vertical motions is depicted in Fig. 2. During period A, the float's pressure and temperature records show relatively long period variations and are $180^{\circ}$ out of phase. This indicates that the float is in a stratified water mass and subject to internal wave activity: an internal wave crest will expose the float to denser water from depth, causing the float to rise [with about one-third the amplitude of the wave (Rossby 1988)]. As the float enters period $B$, both the pressure and temperature records are constant, indicating that there are no vertical motions present and the float is at its hydrostatic equilibrium depth. During period $\mathrm{C}$ the temperature remains constant, but the pressure record exhibits short time-scale fluctuations. This indicates that the float is in a well-mixed, nearly isopycnal layer and subject to large vertical motions, a signature of convective activity. The convective currents induce a drag force that accelerates the float away from its hydrostatic equilibrium level. It is important to note that the velocity of the float, estimated from a time difference of the pressure record, will usually be an underestimate of the velocity of the vertical current; when the float is moving away from its hydrostatic equilibrium level, a vertical current faster that the float velocity is needed to provide the necessary drag force to match the increasing restoring force. To estimate the velocity of the vertical current to which the float is subject, the relationship between the drag and hydrostatic restoring forces may be used.

Three RAFOS floats were deployed on 28 January 1990 from the R/V Endeavor, two floats from the 
freighter M/V Oleander on 9 February 1991, and one float from the $R / \mathbb{V}$ Oceanus on 4 March 1991; all were deployed in the $18^{\circ} \mathrm{C}$ water east of the Gulf Stream. The floats were ballasted to be neutrally buoyant at a depth of approximately 200 to $300 \mathrm{~m}$. Every 20 and $30 \mathrm{~min}$, for the 1990 and 1991 floats, respectively, the ambient pressure and temperature were recorded in the floats' microprocessor memories. (The $1990 \mathrm{ex}-$ periment's sampling interval of $20 \mathrm{~min}$ was chosen because a vertical current of $0.05 \mathrm{~m} \mathrm{~s}^{-1}$ would move a fluid parcel $60 \mathrm{~m}$-a distance less than that of the mixed layer. A larger sampling interval was chosen in 1991 to increase the number of bits saved for each measurement; this sacrifice was made because of some dubious results from the 1990 experiment that were later tied to an error in data retrieval.) Aît the end of their 53-day missions, the floats surfaced and the data were recovered via Systeme Argos, a satellite-based piatform location and data collection system.

\section{Theory}

By considering the forces acting upon a float in a convecting layer, it is possible to develop an expression for the velocity of the vertical currents that are incident upon the float. The vertical momentum equation for a float may written as

$$
M a_{\text {float }}=-\frac{\partial P}{\partial z}-F_{g}+F_{\text {drag }},
$$

where $M$ is the float's mass, $a_{\text {float }}$ is the float acceleration, $\partial P / \partial z$ is the vertical pressure gradient in the water column, $F_{g}$ is the force due to gravity, and $F_{\mathrm{drag}}$ is the drag force induced by vertical currents.

It is convenient to group the vertical pressure gradient force and the gravitational force into a buoyancy force, $F_{\text {buoyancy }}=-(\partial P / \partial z)-F_{g}$. The vertical pressure gradient, due to the lower pressure at the top of the float than at the bottom of the float, pushes the float upward and acts against gravity, which is pulling the float down. These forces will be equal and opposite if $M=V(p) \rho g$, where $V(p)$ is the float volume at pressure $p, \rho$ is the density of the seawater, and $g$ is the acceleration due to gravity. Therefore the float will have no net acceleration if the mass of water it displaces is equal to its own mass; this is Archimedes' principle. The net buoyancy force may be expressed as a function of the displacement from the pressure at which this hydrostatic equilibrium is achieved:

$$
F_{\text {buoyancy }}=\left(\gamma_{\mathrm{sw}}-\gamma_{\text {float }}\right) \operatorname{\rho g} g\left[p-p_{\mathrm{eq}}\right],
$$

where $\gamma_{\mathrm{sw}}$ is the compressibility of seawater, $\gamma_{\text {float }}$ is the compressibility of the RAFOS float, and $p_{\mathrm{eq}}$ is the hydrostatic equilibrium pressure. Since the float is less compressible than seawater $\left(\gamma_{\text {float }}<\gamma_{\text {sw }}\right)$, at pressures greater than $p_{\mathrm{eq}}$ the float will displace a mass of seawater greater than its own mass and will be subjected to an upward restoring force. Likewise, at pressures less than $p_{\text {eq }}$ the float will experience a downward restoring force.
It is this condition that makes the float isobaric in a homogeneous layer.

The total forces acting on the float as expressed in Eq. (1) may now be rewritten more simply as

$$
M a_{\text {float }}=F_{\text {buoyancy }}+F_{\text {drag }} \text {. }
$$

This equation relates that a float in a mixed, convecting layer is subject to two opposing forces: the drag force induced by vertical currents that pulls the float away from its equilibrium level, and the buoyancy force that restores the float to hydrostatic balance.

The drag force is proportional to the square of the relative velocity of the fluid, expressed as the difference of the vertical current velocity $w_{\mathrm{sw}}$ and the vertical float velocity $w_{\text {float }}$. The drag force is also highly dependent upon the float's geometry. Let $C_{d}$ denote the drag coefficient of the float and $A$ be the cross-sectional area of the incident end of the float, so that the drag force may be written

$$
F_{\text {drag }}=\frac{1}{2} \rho C_{d} A\left[w_{\text {sw }}-w_{\text {float }}\right]\left|w_{\text {sw }}-w_{\text {float }}\right| .
$$

By substituting Eq. (2) and Eq. (4) in Eq. (3), the balance between the drag force and buoyancy force in this one-dimensional system can be solved to reflect the velocities of the float and the surrounding current as

$$
\begin{aligned}
\left(w_{\mathrm{sw}}-\right. & \left.w_{\text {float }}\right)\left|w_{\mathrm{sw}}-w_{\text {float }}\right|=\frac{2}{\rho C_{d} A} \\
& \times\left[M a_{\text {float }}-\left(\gamma_{\mathrm{sw}}-\gamma_{\text {float }}\right) V \rho g\left(p-p_{\mathrm{eq}}\right)\right] .
\end{aligned}
$$

Note that the expression on the left-hand side of Eq. (5) preserves the sign (the direction) of the drag force.

Since estimates of $w_{\text {float }}$ and $a_{\text {float }}$ can be calculated from the float's pressure records and all other variables are known, the vertical current velocity $w_{\text {sw }}$ may be solved for algebraically.

\section{Derived quarmatieties}

An important consideration when computing the drag force is the value of the coefficient of drag $C_{d}$. The two ends of the RAFOS floats used in this study are not identical: the top is rounded while the bottom is blunt and has suspended from it a ballast/drop weight. This necessitates the use of directional drag coefficients. The end of the float that the vertical current is incident upon is used to determine which coefficient to apply when calculating the vertical current velocity.

The coefficients were not measured explicitly in this study, but have been estimated from a prototype float that was designed to cycle repeatedly through an approximately $200-m$-thick column of water ( $\mathbb{H}$ Hummon et al. 1991). This behavior was accomplished by changing the float's volume mechanically by a prescribed amount at regular intervals, thereby altering its buoyancy and forcing it to move up and down in the water column between corresponding density sur- 
faces. Such a "cycling" float reaches terminal velocity almost immediately after the float changes its volume and begins moving to its new level of hydrostatic equilibrium. This allows the use of the drag force relation, Eq. (4), to quantify the difference of the drag coefficients for the top and bottom ends of the float. In this way $C_{d}$ for the top (rounded) end of the float was estimated as 1.13 and was estimated as 1.80 for the bottom (blunt) end of the float. The geometry of a cycling float and the RAFOS floats used in this study differ in a few respects: the cycling float's glass housing is $0.095 \mathrm{~m}$ in diameter while the RAFOS float's housing is $0.086 \mathrm{~m}$ in diameter, and the ballast weight that hangs from bottom of the cycling float has a rougher geometry than that hanging below the RAFOS float. Thus, the coefficients derived must be taken only as close approximations to those of the RAFOS floats used in this study.

Due to changes in the density of the surrounding seawater, the pressure of the equilibrium level $p_{\mathrm{eq}}$ for a float will change with time and space. However, this level may be identified from the float pressure data during periods of low convective activity when the float is very near its equilibrium level. When estimating this level, a median filter was used; such a filter is optimized for averaging data with a large error distribution. By applying this filter in a running window of a large width ( 60 points, i.e., $20 \mathrm{~h}$ for 1990 and $30 \mathrm{~h}$ for 1991 data), those relatively few data representing large displacements from equilibrium were excluded from consideration, resulting in a more reliable estimate of the equilibrium position.

Given the many types of vertical motion present in the ocean and the difficulties in defining the exact equilibrium level, a distinction must be made between true convective events and other excursions from neutral buoyancy. This distinction is made by examining the float's temperature record. In a convecting layer, mixing is occurring, and the water mass should be essentially homogeneous. This results in very small temperature fluctuations despite large pressure fluctuations. In a nonconvecting water mass, stratification is present, resulting in large temperature fluctuations if the float is pulled away from equilibrium. Mechanisms capable of pulling the float away from hydrostatic equilibrium in a stratified environment include, but are not limited to, internal wave motion and shear-induced mixing.

\section{Errors}

The errors related to the precision of the RAFOS instrument are small. The pressure resolution of a RAFOS float is $1.0 \times 10^{4} \mathrm{~Pa}$ (corresponding to approximately $1 \mathrm{~m}$ of seawater), with an accuracy of \pm 0.5 $\times 10^{4} \mathrm{~Pa}$. Temperature is accurate to within $0.1^{\circ} \mathrm{C}$ with a resolution of 10 millidegrees (Rossby et al. 1986). Vertical float velocities, estimated from a central difference of pressure, carry uncertainties of $\pm 5.9 \times 10^{-4}$ and $\pm 3.9 \times 10^{-4} \mathrm{~m} \mathrm{~s}^{-1}$ for the 20 -min sampling interval of the 1990 floats and the 30 -min sampling in- terval of the 1991 floats, respectively. The vertical float accelerations, also calculated as a central difference, have errors of $\pm 1.7 \times 10^{-6}$ and $\pm 7.6 \times 10^{-7} \mathrm{~m} \mathrm{~s}^{-2}$ for the two years. These errors are very small due to the averaging effect of the central differences over a large sampling interval; however, this sampling scheme neglects higher-frequency phenomena.

The two other sources of error inherent in the method for estimating vertical velocity result from the determination of the drag coefficient and the equilibrium pressure. The methods used to estimate these quantities were enumerated in the previous section. The resultant error for the drag coefficient is systematic, while the error for the equilibrium pressure is random in nature.

To investigate the random error in the vertical velocity estimate, define a quantity

$$
G \equiv\left(w_{\text {sw }}-w_{\text {float }}\right)\left|w_{\text {sw }}-w_{\text {float }}\right|
$$

and express Eq. (5) as

$$
\begin{aligned}
G=\frac{2}{\rho C_{d} A} & \left\{M \frac{p(t-\Delta t)-2 p(t)+p(t+\Delta t)}{\Delta t^{2}}\right. \\
& \left.-\left(\gamma_{\mathrm{sw}}-\gamma_{\text {float }}\right) V \rho g\left[p(t)-p(t)_{\mathrm{eq}}\right]\right\} .
\end{aligned}
$$

The acceleration has been written in terms of a central difference of pressure, enabling the error in $G(\delta G)$ to be written in terms of the errors in the pressure $p(\delta p)$, and in the hydrostatic equilibrium pressure $p_{\mathrm{eq}}\left(\delta p_{\mathrm{eq}}\right)$. Equation (7) then takes the form

$$
\begin{aligned}
G+ & \delta G=\frac{2}{\rho C_{d} A} \\
\times & \left\{M\left[\frac{p(t-\Delta t)-2 p(t)+p(t+\Delta t)}{\Delta t^{2}} \pm \frac{\sqrt{6} \delta p}{\Delta t^{2}}\right]\right. \\
& \left.-\left(\gamma_{\mathrm{sw}}-\gamma_{\mathrm{float}}\right) \operatorname{V\rho g}\left[p(t) \pm \delta p-p(t)_{\mathrm{eq}} \pm \delta p_{\mathrm{eq}}\right]\right\}
\end{aligned}
$$

Thus, $\delta G$ is

$$
\begin{aligned}
\delta G= \pm\left\{\frac { 2 } { \rho C _ { d } A } \left[\frac{\sqrt{6} M}{\Delta t^{2}} \delta p\right.\right. & +\left(\gamma_{\mathrm{sw}}-\gamma_{\text {float }}\right) \\
& \left.\left.\times V \rho g\left(\delta p+\delta p_{\mathrm{eq}}\right)\right]\right\} .
\end{aligned}
$$

For a known uncertainty in the pressure of $\delta p=1.0$ $\times 10^{4} \mathrm{~Pa}$ and an assumed, and likely overestimated, error in the equilibrium pressure of $\delta p_{\mathrm{eq}}=10.0 \times 10^{4}$ $\mathrm{Pa}$, the error in $G$ is estimated to be $3.94 \times 10^{-4} \mathrm{~m}^{2} \mathrm{~s}^{-2}$. Since the vertical current velocity $w_{\mathrm{sw}}$ is proportional to the square root of $G$, the maximum error in $w_{\text {sw }}$ occurs when there is no float acceleration and the float is at hydrostatic equilibrium. This maximum error is estimated to be $\delta G^{1 / 2}=0.019 \mathrm{~m} \mathrm{~s}^{-1}$. The error decreases rapidly as the magnitude of $G$ increases; the 
influence of $\delta G$ is ciminished by the application of the square root to a greater argument. This fact is demonstrated in Fig. 3. Therefore, during times of large $\left(>40 \times 10^{4} \mathrm{~Pa}\right)$ displacements from equilibrium, error in the vertical velocity estimates will be less than 0.005 $\mathrm{m} \mathrm{s}^{-1}$. This situation is advantageous since the error will be small when convection is occurring and will be large only when there is no convection, a state of reduced interest to this study. Less fortunately, the error limits the usefulness of the technique to studies of internal wave activity, although in this case the error in $p_{\text {eq }}$ would be much less than the $10 \times 10^{4} \mathrm{~Pa}$ assumed previously.

The error in $C_{d}$ stems from the previously discussed approximation of its magnitude. Note that the estimation of the vertical velocity depends on $C_{d}^{1 / 2}$, not $C_{d}$ itself, thus reducing its contribution to the total error. A possible $\pm 25 \%$ error in $C_{d}$ would result in an under-/overestimate of the vertical velocity on the order of millimeters per second for small displacements from equilibrium, and less than $0.015 \mathrm{~m} \mathrm{~s}^{-1}$ at large displacements. This offset is shown in Fig. 3.

\section{Results}

All six floats completed their missions and data retrieval was successiul. Several of the floats were eventually advected out of the western Sargasso Sea and into the Gulf Stream, transporting them rapidly to the northeast. One float crossed the Gulf Stream and spent a third of its lifetime in the near-surface waters of the Newfoundland Basin. The launch and surface information for both the 1990 and 1991 floats is shown in Table 1.

The floats were exposed to both homogeneous and stratified water masses. A float in a stratified water mass

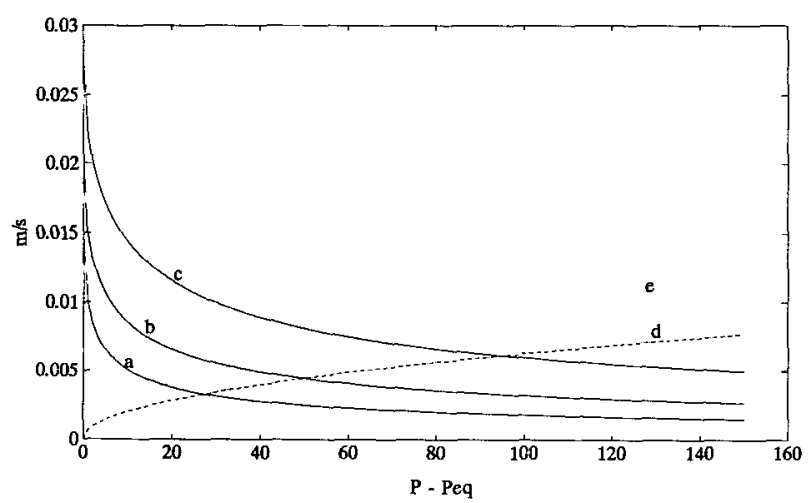

FIG. 3. Error in vertical velocity estimates as a function of displacement from equilibrium. For curves (a), (b), and (c), with assumed errors in the equilibrium depth of 5,10 , and $20 \mathrm{~m}$, respectively, the magnitude of the error in the velocity decreases rapidly as the magnitude of displacement increases. Curves (d) and (e) denote the difference of vertical velocity estimates computed with two different drag coefficients, demonstrating the offset produced by a systematic error in $C_{d}$. The velocities computed with a $+25 \%$ (d) and a $-25 \%$ (e) error in $C_{d, \text { end }}$ differ by millimeters per second. The use of a greater $C_{d}$ will therefore result in an underestimate of the vertical velocity.
TABLE 1. Launch, surface positions, and dates for the floats used in this study.

\begin{tabular}{|c|c|c|}
\hline & Launch position & Launch date \\
\hline Float number & Surface position & Surface date \\
\hline 229 & $\begin{array}{l}36^{\circ} 42.5^{\prime} \mathrm{N}, 69^{\circ} 20.2^{\prime} \mathrm{W} \\
37^{\circ} 11.8^{\prime} \mathrm{N}, 70^{\circ} 44.0^{\prime} \mathrm{W}\end{array}$ & $\begin{array}{l}9 \text { February } 1991 \\
2 \text { April } 1991\end{array}$ \\
\hline 230 & $\begin{array}{l}36^{\circ} 47.5^{\prime} \mathrm{N}, 69^{\circ} 20.2^{\prime} \mathrm{W} \\
44^{\circ} 58.4 \mathrm{~N}, 43^{\circ} 58.3^{\prime} \mathrm{W}\end{array}$ & $\begin{array}{l}9 \text { February } 1991 \\
2 \text { April } 1991\end{array}$ \\
\hline 231 & $\begin{array}{l}36^{\circ} 05.1^{\top} \mathrm{N}, 70^{\circ} 03.7^{\prime} \mathrm{W} \\
38^{\circ} 22.7 \mathrm{~N}, 51^{\circ} 22.7^{\prime} \mathrm{W}\end{array}$ & $\begin{array}{l}4 \text { March } 1991 \\
26 \text { April } 1991\end{array}$ \\
\hline 234 & $\begin{array}{l}35^{\circ} 22.8 \mathrm{~N}, 70^{\circ} 01.5^{\prime} \mathrm{W} \\
37^{\circ} 21.4^{\prime} \mathrm{N}, 66^{\circ} 05.0^{\prime} \mathrm{W}\end{array}$ & $\begin{array}{l}28 \text { January } 1990 \\
21 \text { March } 1990\end{array}$ \\
\hline 235 & $\begin{array}{l}36^{\circ} 11.6 \mathrm{~N}, 70^{\circ} 29.1^{\prime} \mathrm{W} \\
35^{\circ} 02.0^{\prime} \mathrm{N}, 62^{\circ} 16.7^{\prime} \mathrm{W}\end{array}$ & $\begin{array}{l}28 \text { January } 1990 \\
21 \text { March } 1990\end{array}$ \\
\hline 236 & $\begin{array}{l}36^{\circ} 30.0^{\prime} \mathrm{N}, 70^{\circ} 29.0^{\prime} \mathrm{W} \\
36^{\circ} 26.6^{\prime} \mathrm{N}, 69^{\circ} 01.6^{\prime} \mathrm{W}\end{array}$ & $\begin{array}{l}28 \text { January } 1990 \\
21 \text { March } 1990\end{array}$ \\
\hline
\end{tabular}

is subject to internal wave activity that is characterized by undulatory pressure records with corresponding changes in temperature. Conversely, a float in a homogeneous water mass exhibits a pressure record with no wavelike behavior, and temperature fluctuations are on the order of hundredths of a degree. Evidence of convective currents is to be expected only in homogeneous waters (Leaman and Schott 1991).

Since the floats were not acoustically tracked in this study, the temperature records, coupled with the pressure records, play a vital role in determining the approximate location of the floats. The complete pressure and temperature records for 1990 float 235 and 1991 float 230 are shown in Figs. 4 and 5. These two records were chosen from all six floats' records because they encompass a wide range of water masses and accompanying float behaviors. Both floats began their missions in the $18^{\circ} \mathrm{C}$ water and were eventually advected into the Gulf Stream, as indicated by the gradual shoaling and decrease in temperature that occurs after approximately day 55 for float 235 and day 69 for float 230. (These changes are consistent with their subsequent surface locations.) Note the shallow $(<200$ $\times 10^{4} \mathrm{~Pa}$ ) neutral buoyancy pressure of float 235 while it was in the Sargasso Sea; as a result of a slight error in ballasting, this float remained in the warmer $\left(>19^{\circ} \mathrm{C}\right)$ upper-ocean waters. Float 230 is unique in the fact that it found its way into the much cooler, denser Newfoundland Basin waters after day 76 , where it approached the surface.

The records shown in Fig. 4 and Fig. 5 offer a great deal of information describing upper-ocean processes. While it is outside the scope of this paper to scrutinize the entire float records (as well as those of the other four floats), several interesting events warrant closer inspection. An excellent description of float 235's transition from a stratified water mass to a mixed region may be seen in Fig. 6 . The float records prior to ap- 

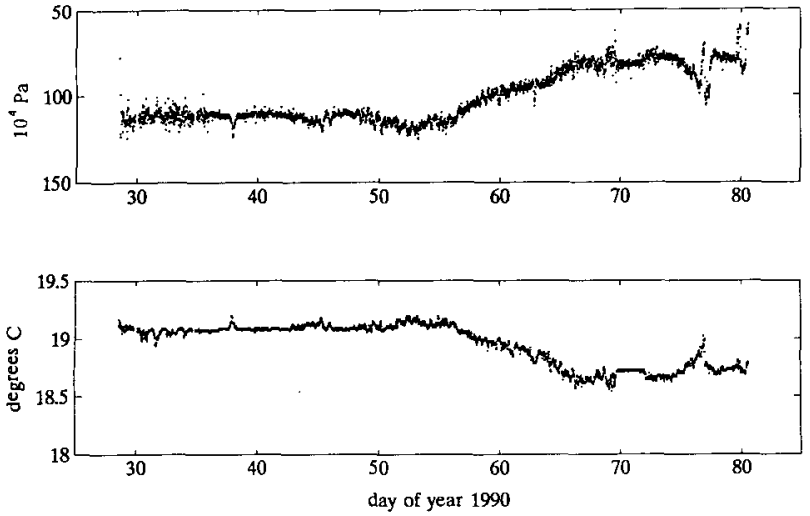

FIG . 4. Pressure (top) and temperature (bottom) for RAFOS float 235. Note the internal wave activity evident for much of its lifetime and convective activity at days $70-72$. Float 235 left the $18^{\circ} \mathrm{C}$ water after day 55 and shoaled as it encountered the cooler waters to the northeast.

proximately day 69.7 exhibit internal wave-like pressure and temperature fluctuations, characterized by a $180^{\circ}$ phase difference: when the float shoals, the temperature decreases. After day 69.7 the temperature was essentially constant and the pressure fluctuated relatively slightly, suggesting that the float encountered a previously mixed patch of water. Also note the inaccuracy inherent in the vertical velocity estimate, due to the small displacements from the estimated hydrostatic equilibrium level.

Figure 7 depicts an intense convective event in the life of float 230 . Note the large $\left(>40 \times 10^{4} \mathrm{~Pa}\right)$ upward excursion of the float in the water column, accompanied by no change in temperature. The upwelling plume of water is estimated to have attained a vertical velocity of $0.042 \mathrm{~m} \mathrm{~s}^{-1}$. The duration of this event
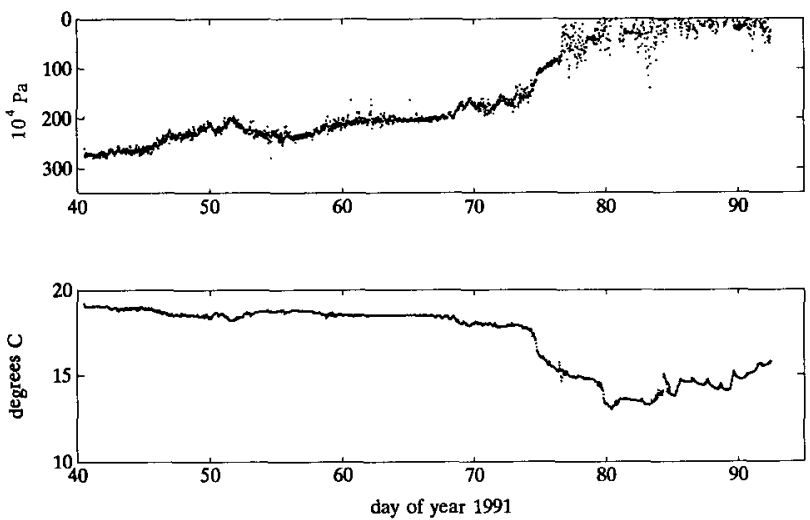

FIG. 5. Pressure (top) and temperature (bottom) for RAFOS float 230. The float left the $18^{\circ} \mathrm{C}$ water after day 69 and entered the Newfoundland Basin after day 76 . In the cold, dense water the float shoaled and approached the surface where it experienced intense vertical currents. Note the convective activity (especially at days 53, 62, and after day 76) and the internal wave activity (especially at days 50 52 and 69-71).
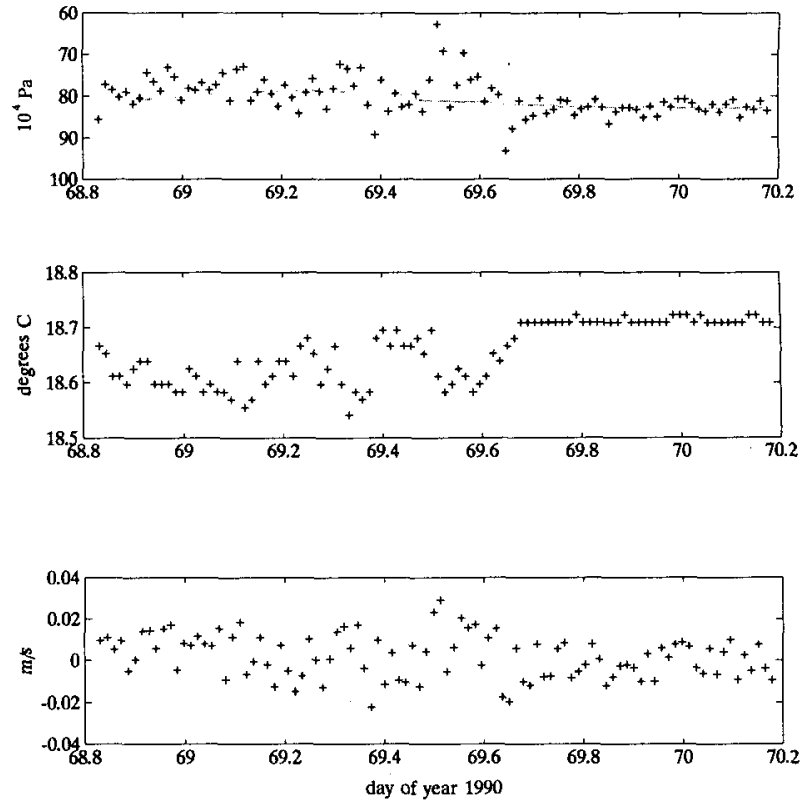

FIG. 6. Pressure [ + ] and hydrostatic equilibrium level [line] (top), temperature (center), and vertical current velocity (bottom) for RAFOS float 235 . On approximately day 69.7 , the float leaves a stratified region (characterized by internal wave activity) and enters a homogeneous region of weak convective activity.

may be conservatively estimated to be $2 \mathrm{~h}$; the float was in the plume for at least that period of time. Immediately following this intense event, milder convective mixing appears to have continued (Fig. 8) for longer than a day. The float often experienced vertical velocities in excess of $0.02 \mathrm{~m} \mathrm{~s}^{-1}$. The temperature of the water again remained almost constant to within the resolution of the float's thermistor.

Float 230's transit into the Newfoundland Basin is shown in Fig. 9. The float encountered a frontal region at day 76.5 , entered the cooler waters, and shoaled. Note the large temperature fluctuations suggestive of interleaving water masses at the frontal region. The temperature record becomes more stable after day 77 , and the float's vertical excursions are large and rapid. The float experienced these conditions for the remainder of its mission with only a few respites from vigorous mixing. In Fig. 10, there is further evidence of highvelocity vertical motion as well as thermal patchiness near the surface. Especially note the temperature increase of approximately $1^{\circ} \mathrm{C}$ associated with no apparent density decrease on day 84.3 (the warm water, if it were as salty as the previously encountered waters and therefore less dense, would have caused the float to sink). The maximum estimated vertical current velocity $-0.093 \mathrm{~m} \mathrm{~s}^{-1}$ occurred on approximately day 83.4. Since the float was often very near, and sometimes on, the surface, convective activity cannot be assumed to be the only mechanism for generating the observed vertical currents; wind-induced mixing (e.g., Langmuir cells) may also contribute to the near-surface vertical 

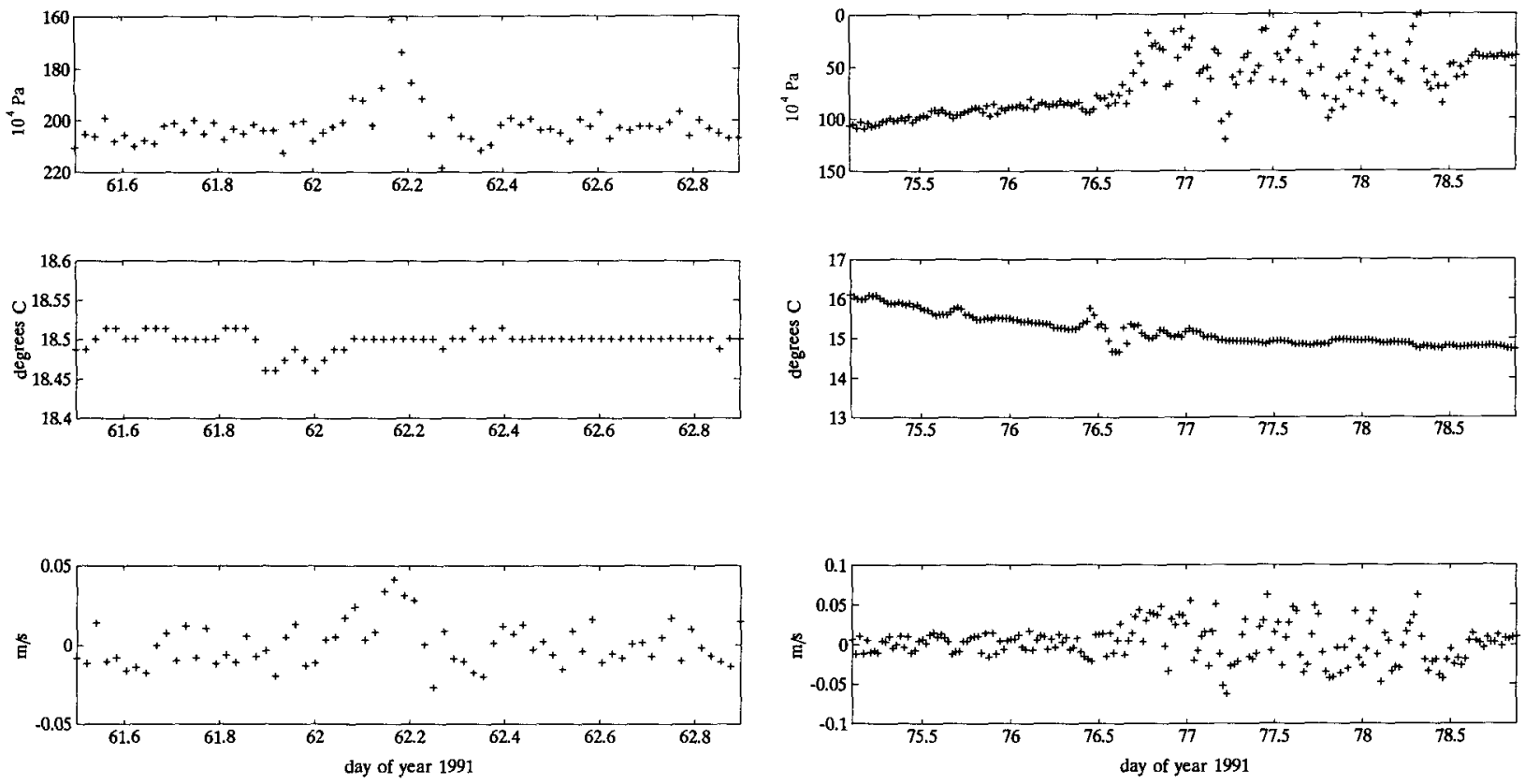

FIG. 7. Pressure [+] and hydrostatic equilibrium level [line] (top), temperature (center), and vertical current velocity (bottom) for RAFOS float 230. Prior to day 62, the float is in a stratified water mass, exhibiting pressure and temperature fluctuations characteristic of internal wave activity. Note the large displacement from equilibrium at day 62.2, indicative of an intense upwelling plume of water; the temperature was constant and the vertical velocity was estimated to have reached $0.042 \mathrm{~m} \mathrm{~s}^{-1}$.
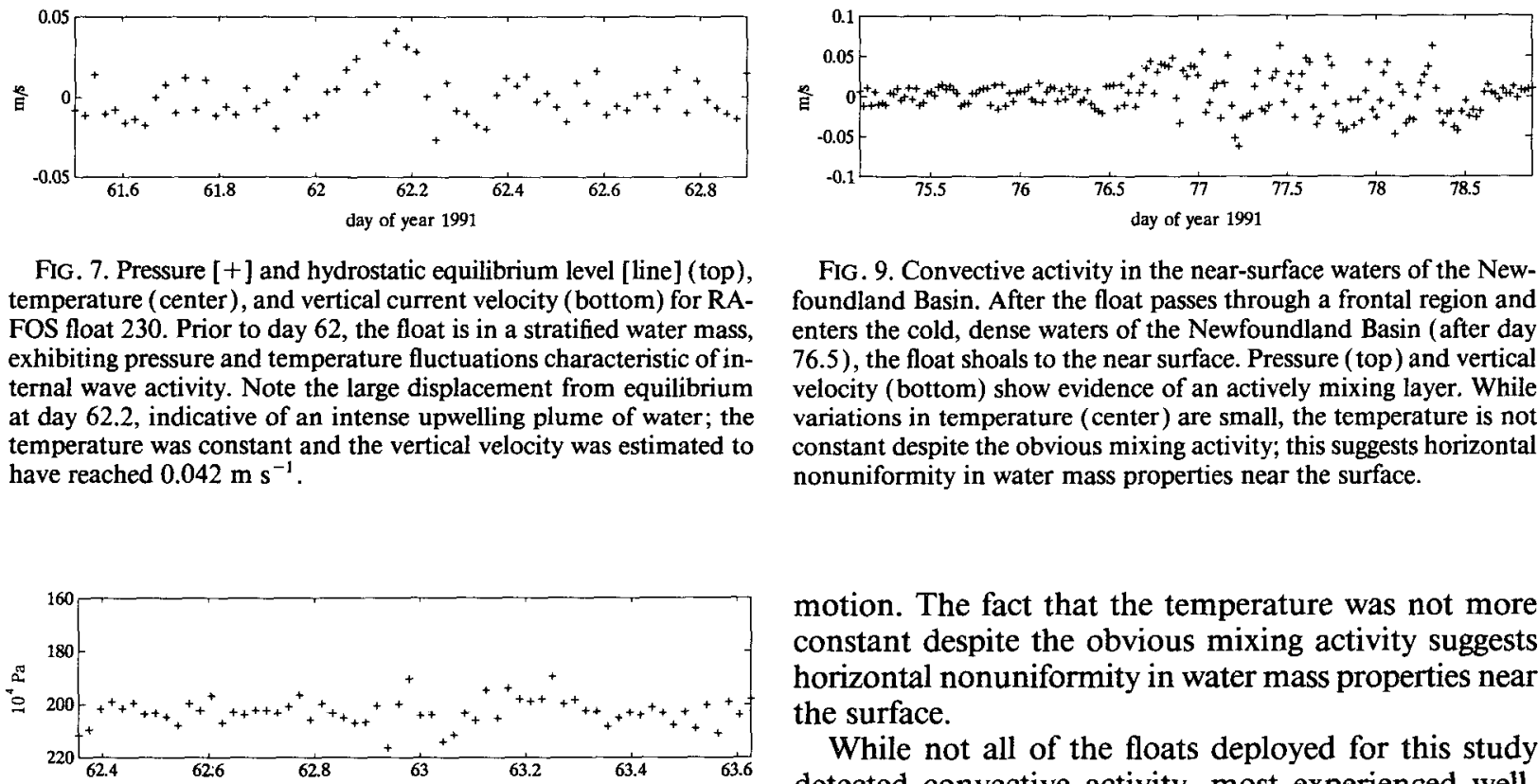

FIG. 9. Convective activity in the near-surface waters of the Newfoundland Basin. After the float passes through a frontal region and enters the cold, dense waters of the Newfoundland Basin (after day 76.5), the float shoals to the near surface. Pressure (top) and vertical velocity (bottom) show evidence of an actively mixing layer. While variations in temperature (center) are small, the temperature is not constant despite the obvious mixing activity; this suggests horizontal nonuniformity in water mass properties near the surface.

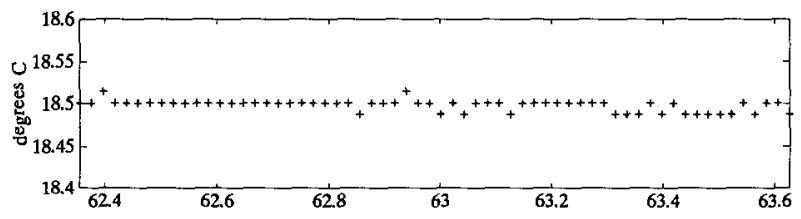

motion. The fact that the temperature was not more constant despite the obvious mixing activity suggests horizontal nonuniformity in water mass properties near the surface.

While not all of the floats deployed for this study detected convective activity, most experienced welldefined convective events with both large upward and downward velocities. Some of these events were shortlived, with only one or two pressure or temperature measurements that suggested convective activity. In these cases, the event's duration is known only to be less than the sampling interval: sampling pressure and temperature once every 20 or $30 \mathrm{~min}$ is insufficient for an adequate description of the convective event.

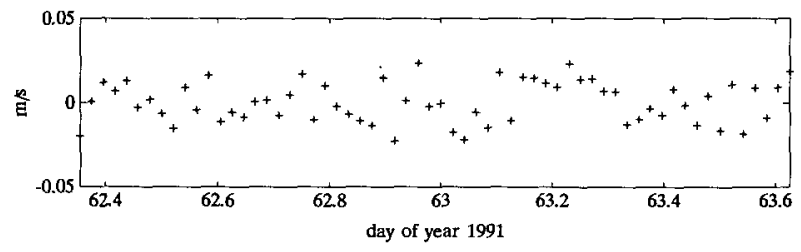

FIG. 8. A closer examination of the period following the intense convective event depicted in Fig. 7. Note that the undulatory pressure record (top) is accompanied by very small temperature fluctuations (center). The short time scale of the pressure fluctuations coupled with the nearly constant temperature are suggestive of convective activity.

\section{Discussion}

The primary objective of this study was to evaluate a simple technique for monitoring convection in deep mixed layers. The method is very similar to the techniques employed by Voorhis and Webb (1970) and Gascard and Clarke (1983), both of which were shipdeployed and -tracked float techniques. The approach here was to adapt the standard RAFOS float technology to the measurement of vertical velocity for extended periods of time. It was decided not to add the slanted vanes and compasses (to measure the rotation of the 

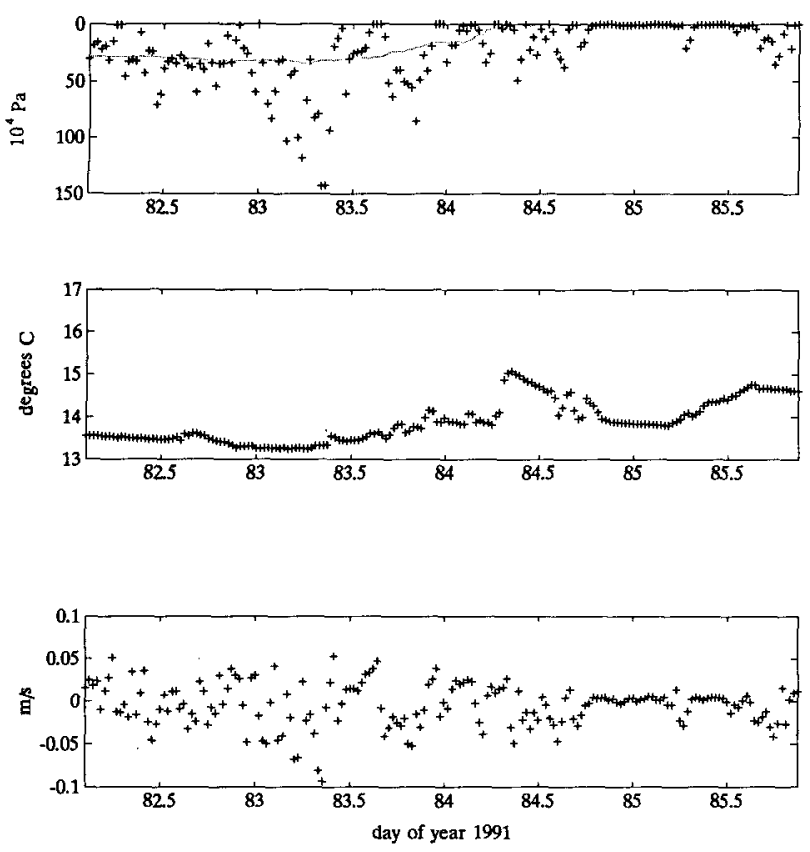

FIG. 10. More convective activity in the near-surface waters of the Newfoundland Basin. The largest observed vertical velocity of -0.093 $\mathrm{m} \mathrm{s}^{-1}$ occurs at day 83.4. Note the nonhomogeneity of the waters, especially at day 84.3 where there is a large $\left(\approx 1^{\circ} \mathrm{C}\right)$ increase in temperature with no apparent decrease in density. Since the float was often very near (or on) the surface, convective activity cannot be assumed to be the only mechanism for generating the observed vertical currents; wind-induced mixing (e.g., Langmuir cells) may account for some of the near-surface vertical motion.

float induced by a vertical flow) that were used in the previous studies so that no modifications to the RAFOS float design would be necessary. The idea was to recognize that vertical motion will pull the float away from its equilibrium depth. The resulting depth change is a measure of the quadratic drag acting on the float, and using a suitable model, it is possible to recover the vertical velocity. As a result, due to the nonlinear nature of the technique, the method is most effective for the measurement of large vertical velocities characteristic of deep convective motion. While the technique clearly has limitations for the study of small-amplitude motions such as internal waves, its simplicity and low cost makes it attractive for the study of deep convection and mixing in regions that are otherwise difficult to access and monitor.

The RAFOS float technology that was in use at this study's inception had a memory limitation of $8 \mathrm{kB}$, which was adequate for its original purpose. For this study, however, it was a serious limitation. (Systeme Argos imposes another constraint in that the data transfer rate to the satellite is low, typically $1 \mathrm{kB} \mathrm{day}^{-1}$.) To extend the duration of the experiment for as long as possible, the sampling interval was set at 20 and 30 min in 1990 and 1991, respectively. It was thought that $20 \mathrm{~min}$ would be a reasonable compromise: at $0.05 \mathrm{~m} \mathrm{~s}^{-1}$ a fluid parcel moves $60 \mathrm{~m}$, or a distance less than the depth of the mixed layer. It is clear, however, that there can be very substantial accelerations during this time. Unfortunately, since the acceleration is computed as a second difference over twice the sampling interval, it may be significantly underestimated. Nonetheless, the results are encouraging, and it is clear that better preprocessing of the raw data is required to meet future accuracy and resolution requirements while keeping the data storage and transmission requirements to a minimum. For example, one might sample frequently about a point in time, compute the float velocity and acceleration in situ, and save temperature and pressure as offsets to infrequently saved full measurements. In this way, not only can higher frequencies be resolved, but a more accurate picture of the convective activity will be obtained. It may also be desirable to monitor the location of the floats during their missions through infrequent acoustic tracking.

The simple time series provided by these instruments can be used to infer intensity, duration, and intermittence of deep convection. The corresponding temperature record, when coupled to the pressure data, can be used to discriminate between convection and internal wave activity. Although internal waves are not well measured, they can be recognized by the much larger temperature fluctuations and the characteristic phase relationship with pressure: when the float shoals, the temperature decreases. For the case of weak acceleration, the pressure perturbation will be proportional to the square of vertical velocity for convection, while for internal waves it will be proportional to the wave amplitude. When the changes are rapid, then the acceleration becomes an increasingly important correction.

Several convective events characterized by upward and downward vertical currents of magnitudes nearing $0.05 \mathrm{~m} \mathrm{~s}^{-1}$ and durations extending up to $2 \mathrm{~h}$ were detected in the western Sargasso Sea. Strong vertical current activity was similarly detected for long durations in the near-surface waters of the Newfoundland Basin, with vertical velocities in one case exceeding $0.09 \mathrm{~m} \mathrm{~s}^{-1}$. These findings are consistent with past observational work on mixed-layer oceanic convective processes.

These results are encouraging. By using off-the-shelf RAFOS float technology, a simple technique has been developed for measuring convection and other upperocean processes in inaccessible areas for long periods of time. This technique is optimized for the detection and measurement of intense vertical currents. Further refinements in the sampling procedure for future studies should increase the accuracy of the measurement of vertical float acceleration and allow for better resolution of high-frequency phenomena.

Acknowledgments. The authors would like to gratefully acknowledge the support of their research under ONR Grant N0001490J1486 and express their thanks to those who contributed to the success of the project. 
Included in this group are Mr. Jim Fontaine of URI and Mr. Don Dorson of Bathy Systems Inc., who were instrumental in the design, construction, and programming of the floats. Many thanks are extended to those who aided in float deployment: the crew of the $\mathrm{R} / \mathrm{V}$ Endeavor, Bermuda Container Line and the crew of their freighter Oleander, and Dr. Peter Worcester of WHOI and the crew of the R/V Oceanus. The authors also appreciate the aid of Ms. Julia M. Hummon, Ms. Sandra Anderson-Fontana, Mr. Kenneth S. Casey, and Mr. Stephan Howden who assisted with the data processing and in the development of this manuscript.

\section{REFERENCES}

Gascard, J-C., and R. A. Clarke, 1983: The formation of Labrador Sea water. Part II: Mesoscale and smaller-scale processes. J. Phys. Oceanogr., 13, 1779-1797.

Hummon, J., T. Rossby, E. Carter, J. Lillibridge, III, M. Liu, K. Schultz-Tokos, S. Anderson-Fontana, A. Mariano, 1991: The anatomy of Gulf Stream meanders. A University of Rhode Is-
land/Graduate School of Oceanography Data Report, vol. 2, 231-239.

Jenkins, W. J., 1982: On the climate of a subtropical ocean gyre: Decade timescale variations in water mass renewal in the Sargasso Sea. J. Mar. Res., 40(Suppl.), 265-290.

Leaman, K. D., and F. Schott, 1991: Hydrographic structure of the convection regime in the Gulf of Lions: Winter 1987. J. Phys. Oceanogr., 21, 573-596.

McCartney, M. S., and L. D. Talley, 1982: The subpolar mode water of the North Atlantic Ocean. J. Phys. Oceanogr., 12, 11691188.

Rossby, T., 1988: Five drifters in a Mediterranean salt lens. DeepSea Res., 35(9A), 1635-1663.

- D. Dorson, and J. Fontaine, 1986: The RAFOS system. $J$. Atmos. Oceanic Technol., 3, 672-679.

Schott, F., and K. D. Leaman, 1991: Observations with moored acoustic Doppler current profilers in the convective regime in the Gulf of Lions. J. Phys. Oceanogr., 21, 556-572.

Talley, L. D., and M. E. Raymer, 1982: Eighteen degree water variability. J. Mar. Res., 40(Suppl), 757-775.

Voorhis, A. D., and D. C. Webb, 1970: Large vertical currents observed in a winter sinking region of the northwestern Mediterranean. Cah. Oceanogr., 22, 571-580.

Worthington, L. V., 1959: The $18^{\circ}$ water in the Sargasso Sea. DeepSea Res., 5, 297-305. 